\title{
O movimento de corte (sob uma falsa sensação de presente) Observações (a)cerca da Disseminação de Jacques Derrida
}

\author{
Ana Carolina Teixeira Pinto (UFFS)
}

\section{Resumo}

Este texto crítico analisa o movimento de corte feito por Jacques Derrida no conjunto de textos do livro Disseminação, de 1972, mais especificamente o texto "La double séance", publicado inicialmente na revista Tel Quel (No 41 e 42) em 1970 e "Hors Livre (Préfaces)", agregado posteriormente. O jogo citacional textual, além do próprio jogo gráfico feito na forma da organização do texto derridiano, são pensados aqui como movimentos de um jogo textual/cênico. Para tanto, elaboramos um discurso com inferências a diferentes recursos artísticos/lúdicos como o jogo de xadrez, o mimodrama, o cinema, a tourada e o movimento de um leque.

Palavras-chave: polissemia, disseminação, jogo citacional.

\begin{abstract}
This critical text analyzes the cutting movement performed by Jacques Derrida in the texts published in the book Dissemination of 1972, more precisely the text "La double séance" published initially in the magazine Tel Quel (41 and 42) in 1970 and "Hors Livre (Préfaces)" added afterwards. The text quotation game, beyond the graphic game itself done in the form in which the Derridian text is organized, are thought here as movements in a textual/scenic game. For that, we elaborated a speech with inferences to different artistic/playful resources such as the game of chess, mimodrama, cinema, bullfight and the movement of a hand fan.
\end{abstract}

Keywords: polysemy, dissemination, quotation game. 
${ }^{1}$ In: DERRIDA, Jacques. Marges de la Pbilosophie. 1972.

${ }^{2}$ DERRIDA, Jacques. La dissémination. 1972.

${ }^{3}$ BUSSARELLO, R. Dicionário Básico: Latino-Português.1998, p. 36.
Em 1971, Jacques Derrida “comunica" "Signature événement contexte" no Congrès International des Sociétés de philosophie de langue française em Montréal. Em uma operação minuciosamente cautelosa, Derrida problematiza a questão da comunicação, em relação ao conceito corrente de contexto e de sentido, justamente em uma comunicação em um congresso intitulado "A comunicação". Neste texto, questiona a polissemia, entendida como a faculdade de uma palavra apresentar diferentes sentidos dependendo do contexto no qual está inserida. Este questionamento é feito primeiro por meio de uma insuficiência teórica do conceito corrente de contexto e segundo pela generalização e deslocamento do conceito de escrita. Para o teórico o conceito de escrita não pode ser entendido como uma categoria de comunicação se pensado como transmissão de pensamento.

Esta construção de uma polissemia das dobras toma corpo em um conjunto de textos seus cronologicamente anteriores publicados em um único livro intitulado La dissémination ${ }^{2} \mathrm{em}$ 1972. O livro é composto por quatro partes independentes-dependentes: "Hors Livre (Préfaces)", "La pharmacie de Platon", "La double séance" y "La dissémination".

No ano de 1969, o texto "La double séance", parte essencial da coletânea, é inicialmente comunicado em duas sessões do Círculo de Estudos Teóricos e posteriormente publicado na revista Tel Quel ( $\mathrm{n}^{\text {os }} 41$ e 42) em 1970. Em 1969, a revista Critique publica parte do texto que leva nome ao livro La dissémination.

"La double séance" inicia uma reflexão sobre a polissemia que vai levar à substituição (movimentação) deste conceito hermenêutico pelo dispositivo operatório disseminação. Mas para chegar a esse ponto, Derrida nos insere em uma trama conceitual, e ao mesmo tempo ficcional, em sua leitura através do que chamou de hímen posicionado entre os textos de Platão e de Stéphane Mallarmé.

Graficamente falando, ou melhor, escrevendo, o hímen é o espaço em branco situado entre um trecho de Filebo de Platão e o texto "Mimique" de Mallarmé. O diálogo de Sócrates e Protarco, que inicia "La double séance", encontra-se justificado no lado esquerdo da folha na forma de um L maiúsculo de ponta cabeça. Abaixo dele, justificado à direita em forma de retângulo o comentário de Mallarmé sobre Pierrot assassin de sa femme.

Em forma de 'L'. É em forma de 'L' que o cavalo se movimenta em um tabuleiro de xadrez. O cavalo, do latin, caballus $^{3}$, é uma peça, um personagem, um guerreiro, um operador de carga, de trabalho. O cavalo trabalha. O cavalo é um operário. O cavalo é um operador. O que carrega o cavalo de Platão-Derrida na dupla sessão? O cavalo carrega "Mimique" e com ele, em movimentos cavalgantes em um encavalgamento contí- 
nuo, a pergunta “o que é literatura?". Afinal onde estaria o fim do poema platônico-mallarmeano-derridiano? O fim do poema estaria em sua tentativa explicatória, por isso em um trote de tabuleiro de xadrez, não darei explicações, me movimentarei apenas, me movimentarei acerca da Disseminação derridiana.

\section{Movimento primeiro - o cavalo}

O movimento de leitura se inicia na segunda página do livro XVIII de Filebo, coincidentemente ou não, no meio do diálogo (na versão eletrônica da elogiada edição da UFPA de cinquenta e seis páginas com tradução de Carlos Alberto Nunes, o trecho começa exatamente na página vinte e oito $\left.{ }^{4}\right)$. Nessa conversa, os debatedores discutem a respeito do que consiste o bem: no prazer e no deleite ou no saber e na memória, ou em outra coisa ainda ${ }^{5}$. Para avançar nesta questão, discursam sobre o prazer, a sabedoria e a memória para no final apontar para três adjetivos que estariam mais próximos do bem: simetria, beleza e verdade, seguidos então primeiro da sabedoria e por fim do prazer. No entanto, no trecho escolhido por Derrida, Sócrates e Protarco pensam sobre o discurso, verdadeiro ou falso, que seria a soma da memória, das sensações e a da reflexão. A alma é comparada a um livro, o qual conta com a colaboração de dois artesãos, um escritor e um pintor. Ambos escrevem e pintam sobre o discurso do passado, presente e futuro e que os prazeres e dores da alma, ou seja, do discurso, do livro, da representação, podem anteceder os do corpo, isto é, da realidade. Para Derrida, Filebo define e ilustra a mímesis sem nomeá- $\mathrm{la}^{6}$. Sem pressa de definir um pensamento sobre a mímesis, a questão não apenas volta sempre no texto derridiano, como é parte fundamental de sua trama, para cuja montagem Derrida resgata outros diálogos platônicos como Crátilo, Banquete, Fedro, Sofista e A República. A oitava nota de "La double séance" resume a complexidade de definições e suas contradições nos diálogos platônicos. Para Evando Nascimento

o interesse da nota é o de colocar o problema do mimetologismo na perspectiva de um texto que funda a imensa tradição interpretativa da mimesis em geral e da mímesis literária em particular. Aí incluindo-se a retomada do conceito por Aristóteles em sua Poética, a despeito das diferenças de formulação. Todo o julgamento da literatura no Ocidente passa pelo crivo dessa máquina discursiva, montada desde Platão segundo o critério da verdade. A dupla cena de julgamento e condenação que se representa no livro $\mathrm{X} \mathrm{d}^{\prime} A$ República é um de seus componentes mais poderosos ${ }^{7}$.
${ }^{4}$ PLATÃO, 427-347 a.C. Filebo. 2000.

${ }^{5}$ Ibid., p. 1. "Sócrates - Ora bem: o que Filebo afirma, é que, para todos os seres animados, o bem consiste no prazer e no deleite, e tudo o mais do mesmo gênero. De nossa parte, defendemos o princípio de que talvez não seja nada disso, mas que o saber, a inteligência, a memória e tudo o que lhes for aparentado, como a opinião certa e o raciocínio verdadeiro, são melhores e de mais valor que o prazer, para quantos forem capazes de participar deles, e que essa participação é o que há de mais vantajoso pode haver para os seres em universal, presentes e futuros. Não foram esses pontos, Filebo, mais ou menos, que cada um de nós defendeu?".

${ }^{6}$ A publicação em francês é usada apenas como fonte para solucionar dúvidas da tradução para o espanhol feita por José Martin Arancibia. Para todas as citações e comentários usaremos a seguinte edição em espanhol:

DERRIDA, Jacques. La

Diseminación, 1997, p. 274.

${ }^{7}$ NASCIMENTO, Evando.

Derrida e a Literatura. 2001, p. 46. 
${ }^{8}$ DERRIDA. La Diseminación, p. 341 .

${ }^{9} \mathrm{O}$ título da encenação, PIERROT ASSASSIN DE

$S A F E M M E$, no texto de Derrida está escrito assim, em maiúsculas.

${ }^{10}$ MALLARMÉ. Mímica. In: DERRIDA. La Diseminación, p. 265. Tradução nossa.

${ }^{11}$ DERRIDA. La Diseminación, p. 292.

12 Ibid., p. 299. "Lo que Mallarmé tiene entre las manos es una segunda edición, posterior en cuatro años a la primera, en cinco años al propio espectáculo. La noticia del autor ha reemplazado al prefacio de un tal Fernand Beissier".

${ }^{13}$ Ibid., p. 300
Ao chegar ao final da citação-texto de Platão, o leitor de Derrida se depara com uma observação de Sócrates, sugerindo que toda aquela argumentação serve também para responder a outra questão. Que questão será essa?

E o cavalo completa seu movimento, revestindo-se de um manto muito fino, quase inexistente, um hímen que contempla a leitura do texto de Mallarmé.

\section{Movimento segundo - o retângulo}

Um hímen que contempla a leitura da arte do mímico, entre o sonho e a ideia. Ao ler "Mimique" na forma como está disposta na folha, ou seja, após a leitura do diálogo platônico, o leitor se depara novamente com a questão da mímesis. O retângulo narrativo introduz a problemática da performance do mímico, destacando-a como a arte que estaria mais cerca dos princípios. $\mathrm{O}$ ator, todo de branco, como uma página ainda não escrita, em um solilóquio mudo, traduz o silêncio.

O retângulo está dividido em dois parágrafos (mas não em duas metades, pois não há simetria nem separação de ideias, como expõe a nota trinta ${ }^{8}$ ), no primeiro a ideia de silêncio é apresentada juntamente com o comovedor Paul Magueritte, autor e executor do solilóquio. Na sequência, a performance em si é nomeada e pensada, PIERROT ASS ASSIN DE SA FEM$M E^{9}$. E para ilustrar o que chama de "instinto simplificador direto", uma suposta citação que discursa sobre a atuação:

\footnotetext{
A cena não ilustra mais que a ideia, não uma ação efetiva, em um hímen (de onde procede o Sonho) vicioso mas sagrado, entre o desejo e o cumprimento, a penetração e sua lembrança: aqui avançando, rememorando ali, no futuro, no passado, sob a aparência falsa de presente. Assim opera o Mimo, cujo jogo se limita a uma ilusão perpétua sem romper a lua: instala, assim, um meio, puro, de ficção ${ }^{10}$.
}

O leitor de Derrida, neste momento da leitura, não é avisado da origem de tal citação, no entanto, mais adiante, em seu texto o filósofo revela que não se trata de uma citação senão de um simulacro de explicação ${ }^{11}$. No desdobramento textual do retângulo, somos informados que uma primeira versão de "Mimique" é publicada em 1886 em Revue indépendante, sem título. E a partir daí lemos uma longa busca de diferentes versões, como ocorre na nota quatorze. Mallarmé haveria lido o libreto da atuação do mímico ${ }^{12}$ e talvez, segundo Derrida, até mesmo presenciado tal apresentação, tendo em vista sua relação parental (Mallarmé e Paul Margueritte eram primos) ${ }^{13}$. 
Derrida vai longe na relação entre Mallarmé e Paul Margueritte; das motivações de ambos à produção dos referidos textos e de seus prováveis desdobramentos. No entanto, o emaranhado de fios destecidos mostra ao leitor que por mais longe que se chegue não seria possível chegar a um hipotexto, ou texto primeiro, como sugere Gérard Genette em Palimpsests ${ }^{14}$ (o mesmo Genette citado por Derrida na página 332 ou ainda na página 371 da referida obra).

Poderíamos continuar um bom tempo, para saber onde tinha Pierrot a história paradigmática desse marido que fez cócegas na sua mulher e dessa maneira lhe fez, rindo, entregar sua alma. Com todos os fios da comedia dell'arte, encontraríamo-nos presos numa rede sem fim ${ }^{15}$.

E para continuar, e não complementar ou explicar, na nota dezessete Derrida cita alguns exemplos destes fios de Pierrot. Além disso, revela uma citação encontrada no livreto, de Teófilo Gautier, que aponta para um diálogo textual: "A história de Pierrot que fez cócegas em sua mulher, e desta maneira, rindo, a fez entregar a alma"16. Este processo coloca em xeque a pesquisa bibliográfica, a busca de fontes, bem como uma análise biográfica, pois tudo em um texto está tramado e não apenas exposto ou copiado, mimetizado. ${ }^{17} \mathrm{O}$ texto mostra e esconde, o texto não é apenas polissêmico, é disseminado.

\section{Movimento terceiro - o 'mimodrama'}

O texto de Mallarmé não relata a obra Pierrot assassin de sa femme, mas a analisa, ou, ainda, a teoriza, como se pode verificar nos trechos citados anteriormente. A representação lida em tal livreto nos é exposta por Derrida que revela tratar-se de uma segunda edição impressa cinco anos após o espetáculo. Esta edição contém um prefácio de Fernand Beissier, apresentado por Derrida como "um tal Fernand Beissier"18, que descreve o 'mimodrama' e a reação de seu público.

A encenação narrava a história de Pierrot que, estando sozinho, contava como matou Colombina, a qual o havia enganado. Enquanto Colombina dormia, Pierrot a amarra na cama e a mata de cócegas nos pés. Colombina morre dando gargalhadas entre o prazer e a dor, entre o crime e o orgasmo. Não esqueçamos que se trata de um solilóquio, estando portanto apenas Pierrot na cena em que, como narrador mudo, encenava o assassino e a assassinada. Pierrot mata e é morto em cena, ou seja, representando ao mesmo tempo em que escreve com gestos
${ }^{14}$ GENET'TE, Gérard.

Palimpsests. 1997.

${ }^{15}$ DERRIDA. La Diseminación, p. 310. Tradução nossa.

${ }^{16}$ Ibid., p. 307. Tradução nossa.

${ }^{17}$ Ibid., p. 339. "O que pode ter acontecido na cabeça de Mallarmé, na sua consciência ou no seu inconsciente não nos importa aqui, sabemos agora por quê. Em todo caso, não interessa em nada para a leitura do texto: tudo nele está urdido, vimos, para prescindir de referências, para acabar com elas". Tradução nossa.

${ }^{18}$ Ibid., p. 299. 
${ }^{19}$ Ibid., p. 337. Tradução nossa.

20 MAJOR, René. Lacan com

Derrida. 2002, p. 204.

21 MALLARMÉ. Mimica. In: DERRIDA. La Diseminación, p. 265. Tradução nossa. sua história, sua representação. A representação é representada. "O mimo não lê seu papel, é também lido por ele"" "Não há semelhança, nem dessemelhança, entre uma presença e uma representação. A cena (da escritura) ilustra apenas uma ideia [...]"20,

não uma ação efetiva, em um hímen (de onde procede o Sonho) vicioso mas sagrado, entre o desejo e o cumprimento, a penetração e sua lembrança: aqui avançando, rememorando ali, no futuro, no passado, sob a aparência falsa de presente ${ }^{21}$.

Esta dupla sessão, que não é apenas dupla, senão múltipla, é uma leitura (a leitura feita por Mallarmé) sobre uma narrativa (a narrativa lida no livreto) sobre uma narrativa (a narrativa sobre uma encenação mímica) sobre uma narrativa (a narrativa recordativa do protagonista que mata sua mulher, que ao contá-la mimicamente a representa). Não esquecendo, é claro, que o que lemos é uma leitura de todas as outras, escrita por Derrida.

\section{Movimento paralelo - o matador}

Esta ambiguidade representada, coincidentemente ou não (e isso para essa leitura não importa), lembra o filme Matador, de Pedro Almodóvar de 1986. No filme, os protagonistas, ambos assassinos, um toureiro renomado e uma advogada, vivem um estranho caso de amor. Seu prazer, que a princípio é matar, revela-se também o de ser morto pela pessoa amada. Na sequência final, ambos realizam, ou melhor, representam, já que planejam cada cena, momentos de paixão carnal que refletem seu prazer maior de assassinar e ser assassinado contemporaneamente ao gozo sexual. Ambos morrem entre gozos e risos, como a representação de Pierrot e Colombina. No entanto, no filme, mesmo sendo a atuação planejada e executada por ambos, é a personagem feminina que logra matar o companheiro e se suicidar em seguida. É ela então a assassina e a assassinada da cena final, posto que o toureiro também é um assassino, matador em outros momentos do filme.

Esta sequência final é narrada por um aluno do toureiro, simultaneamente à sua representação. Isto é, o aluno, suposto vidente, narra o encontro dos dois amantes enquanto este está acontecendo. Elemento esse que revela um véu ou um hímen que separa esta narrativa do sonho, ao mesmo tempo em que o separa da realidade. Uma atuação vivida no presente e contada também no presente, mas sob uma sensação de passado/futuro, visto que o presente é incapturável e para os ouvintes de tal nar- 
ração, um detetive, uma psicóloga e a ex-namorada do toureiro, tal narração era uma possibilidade, ou seja, um futuro, e que tem sua confirmação e desfecho quando já é passado, isto é, quando eles chegam ao reduto do crime/prazer e presenciam a cena final congelada, à espera de espectadores.

E só assim o texto/cena/representação/realidade acontece, ao encontrar os olhos de espectadores/leitores que o vão interpretar. Mas seu sentido, que nunca será único, e se volta sobre si mesmo, ou seja, sob sua própria representação, não poderá, assim como o presente, ser capturado. O sentido sem o encontro do pai, sem a presença do sêmen, que sempre será um desconhecido por sua multiplicidade identitária, será não apenas um duplo sentido, mas um sentido disseminado, um sentido nunca seminado em sua apaternidade.

\section{Movimento circular - "Hors livre”}

Bárbara Johnson, tradutora dos textos de Derrida para a língua inglesa, chama sua introdução a Dissemination de um roadmap, que guia o leitor a algumas das rotas da escritura derridiana. Johnson aponta a impossibilidade de oferecer um sumário de temas essenciais, pois isso seria contra a economia de um texto, como problematiza o próprio Derrida no suposto prefácio "Hors livre". Para a pesquisadora: "Enquanto o leitor espera ler um prefácio de Disseminação, o que ele acha é a palavra disseminação disseminada aqui e lá com um prefácio em prefácios"22.

Nesta abertura "Hors livre (Préfaces)" Derrida aponta uma das teses que irá sustentar, talvez a mais importante desta obra:

Teríamos, a partir de agora, que adiantar que uma das teses - há mais de uma - inscritas na disseminação é justamente a impossibilidade de reduzir um texto como tal aos seus efeitos de sentido, de conteúdo, de tese ou de tema. Não a impossibilidade, talvez, já que se faz normalmente, mas sim a resistência - diremos a restância - de uma escritura que não se faz mais do que se deixa fazer ${ }^{23}$.

Por isso descreve, neste texto, a impossibilidade de escrever um prefácio, pois este deveria anunciar o sentido da obra. Como anunciar o sentido de uma obra que problematiza a possibilidade de delimitação do sentido? Como reduzir a cadeia da escritura a temas e formalidades estruturais? Por outro lado, Derrida afirma a necessidade de escrevê-lo para apagar dele o texto na lógica do conceito que não pode se pressupor ${ }^{24}$. Considerando a impossibilidade de haver um fora-do-livro, o prefácio seria um simulacro de pós-fácil, como explica a nota dezesseis:
${ }^{22}$ JOHNSON, B. Translator's Introduction. In: DERRIDA. Dissemination. 1981, p. 32. Tradução nossa. "While the reader expects to read a preface to Dissemination, what he finds is the word 'dissemination' disseminated here and there within a preface on prefaces".

${ }^{23}$ DERRIDA. La Diseminación, p. 13.

${ }^{24}$ Ibid., p. 54. 
${ }^{25}$ Ibid., p. 42.

${ }^{26}$ PLATÃO. A República, p. 28.

${ }^{27}$ DERRIDA. La Diseminación, p. 70 , nota 27.

${ }^{28}$ BORGES, Jorge Luis. Obras completas. 2003, p. 13.
Segundo a lógica do relevo, o post-facio é a verdade do prefácio (sempre enunciado "a posteriori”) e o discurso (produzido a partir do saber absoluto). O simulacro do post-facio consistiria em fingir revelar a seu modo o sentido ou o funcionamento de uma linguagem ${ }^{25}$.

Novamente o sentido. O prefácio pressupõe um texto fechado, terminado, que tem sua confirmação, apresentação e aceitação na palavra, discurso do pai. Numa cena de auto-inseminação, a obra já feita é auto-inseminada por ela, pelo pai. Como pondera a nota vinte e sete, o discurso se converte em seu próprio pai, já que nada foge do discurso. Esta ideia também pode ser lida no trecho de Filebo, o L, o movimento do cavalo já é discurso. A própria alma é discurso, é livro.

Sócrates - Acho que nessas ocasiões a alma se assemelha a um livro.

Protarco - Como assim?

Sócrates - A memória, em consonância com as sensações que dizem respeito àquelas ocorrências, é como se escrevesse, por assim dizer, discursos na alma ${ }^{26}$.

E pode ser complementada em Fedro: "que o discurso responda por si mesmo, de si mesmo"27.

É interessante notar como essa não introdução ao texto, esse simulacro de pós-fácil, assim como o mimo/matador, opera como assassino e assassinado. É um discurso de autonegação, ao mesmo tempo que de autoafirmação, um texto que se constrói a partir de sua desconstrução. Um texto que introduz, mas que também argumenta, complementa e questiona os textos que o seguem. Um texto que cita, ou melhor, autocita seus próprios textos. Um texto que não poderia estar fora-do-livro quando se revela igualmente aberto e já disseminador da tese que aponta como uma das teses do livro. Um texto que transborda em seu jogo citacional sobre sua própria existência. Um texto que assim como os outros viverá a impossibilidade de regresso ao pai, pois é assassino e assassinado, é filho e é pai, é sêmen e é semeado. É presença e é representado.

Em 1975 Jorge Luis Borges publica um livro que reúne uma seleção de prólogos escritos por ele a diversos livros de diferentes autores. Prólogos con un prólogo de prólogos inicia com um "Prólogo de Prólogos" escrito pelo próprio autor. Nesse texto Borges revela que ao revisar o volume, encontrou inúmeros outros livros que se hospedavam nele. No entanto, como "O homem de ontem não é o homem de hoje" ${ }^{28}$ se permite mudar ou complementar por vezes seu discurso passado. Borges não se encontra plenamente nos textos por ele escritos, os sentidos não são os mesmos que foram algum dia, talvez. O pai não reconhece o filho. Para retornar ao pai, o filho/texto se transfor- 
ma em outro, e esse outro haveria que se transformar para encontrar seu pai, que já não seria seu pai, também já seria outro.

Ao destacar que na composição dos diferentes prólogos se encontram diferentes livros, e apontando sua mudança enquanto escritor e enquanto leitor, Borges revela a impossibilidade de recoser uma escritura que não conseguiria seguir o rastro de sua origem e por isso não a deslindaria como tal. Borges, que no mesmo prólogo admite desconhecer uma teoria sobre prólogos, poderia quem sabe admitir a existência da fuga do sentido pleno do texto, da impossibilidade de um retorno do encontro com o pai, ou seja, a disseminação. Como podemos ler ainda no simulacro de pós-fácil:

A disseminação abre, sem fim, essa ruptura da escritura que já não se deixa recoser, o lugar no qual nem o sentido, mesmo que fosse plural, nem nenbuma forma de presença, sujeita já ao rastro. A disseminação trata o ponto em que o movimento da significação viria regularmente ligar o jogo do rastro produzindo assim a história. Salta a segurança desse ponto detido em nome da lei. É - pelo menos - correndo o risco desse fazer saltar, como se dispunha a disseminação. E o rodeio de uma escritura de onde não se volta ${ }^{29}$.

"Ao distanciar-se da polissemia, mais ou menos que ela, a disseminação interrompe a circulação que transforma em origem um a posteriori do sentido" 30 . Já neste prefácio a polissemia do sentido de prefácio não dá conta de sua própria existência. O texto vai além de sua significação no Dicionário Littré, "Discours préliminaire mis à la tête d'un livre", ou mesmo no Aurélio, "texto preliminar escrito pelo autor ou por outrem e colocado no começo do livro". Enfim, o texto preliminar em questão não é um texto no começo do livro, porque a existência de tal livro significaria a existência de um circuito fechado, simulacro de um a posteriori do sentido. O livro derridiano se abre em leque, um leque de dobras infinitas de textos, de marcas, de cortes e de sentido.

\section{Movimento de leque}

Em "La double séance" Derrida analisa a possibilidade/ impossibilidade da crítica temática moderna por meio dos exemplos do 'branco' e da 'dobra' em Mallarmé. Ambos os temas são conhecidos da crítica e trabalhados em L'Univers imaginaire de Mallarmé, de Jean-Pierre Richard, de 1961. Esses temas, assim como outros, são apresentados no prefácio de Richard e através desses a noção de tema é questionada. Usando termos de um 'psicologismo' crítico como "estruturas vivas", "pares
${ }^{29}$ DERRIDA. La Diseminación, p. 41.

${ }^{30}$ Ibid., p. 33. 
${ }^{31}$ Ibid., p. 371.

${ }^{32}$ Ibid., p. 374.

${ }^{33}$ Ibid., p. 375.

${ }^{34}$ Ibid., p. 377.

${ }^{35}$ Ibid., p. 387.

${ }^{36}$ Ibid., p. 393. mentais", "figuras benéficas", “equilíbrios acertados", entre outros, sua análise está baseada em uma dialética que anima todo seu tematicismo ${ }^{31}$. Para avançar em sua reflexão, Derrida cita o estudo de Paul Ricoeur sobre a obra de M. Eliade, o qual aponta a dificuldade de construir um léxico de frequências pela característica diacrítica das línguas, "o elemento é nelas menos importante que a distância que o separa dos demais elementos"32. O próprio Richard aponta a diacriticidade como componente que impossibilita a existência de um tema, pois se existe um sistema textual, "a diacriticidade atravessa o texto de parte a parte e não tem núcleo temático, unicamente efeitos de temas que se fazem passar pela coisa mesma ou pelo sentido mesmo" ${ }^{\text {"33 }}$. A repetição semântica do branco e da dobra é rica por sua pobreza e não por sua temática, suas ocorrências revelam sua marcação, seu espaçamento, seu apagamento, sua anulação.

Em um movimento de leque. A polissemia dos "brancos" e das "dobras" se desdobra e se redobra em leque. Porém ler o leque mallarmeano não é somente fazer o inventário de suas ocorrências... É observar que o leque se remarca... ${ }^{34}$

Em um movimento trópico, o nome se marca mediante todas as unidades sêmicas que se possam identificar, o branco como asa, neve, espuma, dobra, página, véu, voo, etc. Movimento analógico, metafórico, metonímico, que põe em xeque seus efeitos de diferença e semelhança. O branco está marcado por uma dobra, uma marca, que marca a cada branco um dos sentidos de sua série semântica e assegura seu espaço de repetição e de produção, não havendo assim sentido próprio. "Não há já sentido próprio e, portanto, metáfora. Tornando tudo metonímico..." ${ }^{\prime 35}$

Assim como em Mallarmé, o texto derridiano em movimento de leque se desdobra e se dobra. Deste modo, ler o leque mallarmeano não é apenas fazer um inventário de suas ocorrências, tampouco é ler o texto derridiano. Em seus textos, as ocorrências da palavra disseminação são inúmeras, afirmando a impossibilidade de definição de um tema para este conjunto de textos, posto que a disseminação tem como marca a reafirmação da fuga do sentido pleno do texto. A disseminação é movimento, marca, repetição, corte e não conceito ou tema:

Se não há, pois, unidade temática ou de sentido total que se reapropiar além das instâncias textuais, num imaginário, numa intencionalidade ou num vivido, o texto já não é a expressão ou a representação (acertada ou não) de alguma verdade que viria a difratar-se ou reunir-se numa literatura polissêmica. É o conceito hermenêutico de polissemia que teria que ser substituído pelo de disseminação ${ }^{36}$. 


\section{Movimento de abertura - a disseminação}

O movimento de abertura de La dissémination, isto é, sua sentença inicial em "Hors livre (Préfaces)", já sugere o questionamento do livro e de seu início. "Este (pois) não haverá sido um livro". ${ }^{37}$ Esta apresentação de uma hipótese feita no futuro do pretérito, a modo de conclusão, prevê o encontro do suposto livro com o leitor. Quando do momento, movimento deste suposto início de leitura, o livro não será um livro. Digo suposto início pois assim como o texto problematiza sua introdução, também o faz a respeito de sua origem, seus limites, seu início e seu fim. Como, depois de toda a leitura deste conjunto de escrituras, afirmar o início de um texto qualquer, ou mesmo de um livro? O texto tem seu início em algum lugar, de forma alguma singular ou único, um lugar já desde sempre plural. Um lugar já costurado e até mesmo pintado pelo discurso interno da alma. O texto inicia muito antes de o leitor abrir o livro, ou melhor, muito antes de o leitor visualizar sua capa. Este texto (pois) já haveria sido disseminado.

E é justamente esta explosão, esta disseminação, que lemos nos inúmeros diálogos com prefácios no prefácio, nas inúmeras citações entre aspas e fora delas de Mallarmé e Platão, em "La double séance", e de Philippe Sollers, em La dissémination. Para Barbara Johnson, a multiplicidade de citações é um dos principais desafios da leitura e tradução deste texto. As citações que às vezes estão entre aspas, outras em itálico, e outras ainda sem nenhuma marcação, no caso do texto La dissémination, não são apenas do romance Numbers [Nombres], de Sollers, mas também de outras obras do escritor. Além disso, outros autores nem sempre identificados são citados como: "Claudel, Lautréamont, Robert Greer Cohn, Montaigne, Freud, Heidegger, Sophocles, Artaud, Hegel, Marx e Mallarmé". ${ }^{38}$ La dissémination segue portanto os traços do romance sobre o qual escolhe refletir, Numbers, de Philippe Sollers, pois sua narrativa é, como afirma Johnson, "explicitamente heterogênea e descontínua: aspas, parênteses, lacunas, cortes, figuras e ideogramas chineses são apenas as manifestações de texto contínuo mais visíveis" ${ }^{\prime 3}$. Neste movimento de disseminação após o que não poderíamos chamar de discussões iniciais, a disseminação é colocada em seu grau máximo de desaprovação/aprovação e a análise dessa seria um movimento de entrada à disseminação derridiana, por isso se faz necessário um outro texto, ou o mesmo escrito em um futuro movimento.
${ }^{37}$ DERRIDA. La Diseminación, p. 7.

${ }^{38} \mathrm{JOHNSON}$, B. Translator's Introduction. In: DERRIDA.

Dissemination, p. 30.

${ }^{39}$ Ibid., p. 29. Tradução nossa.

"The text of the novel is explicitly heterogeneous and discontinuous: quotations, parentheses, dashes, cuts, figures, and Chinese characters are only the most visible manifestations of continual textual upheaval". 


\section{Movimento de corte futuro - o rastro, o resto, o falso início da continuação}

Para este movimento futuro de escritura, o corte/rastro já no presente continua, pois seu início se perdeu num passado inatingível. Então, será o movimento de escritura futuro, presente? A modo de visualização de uma alimentação do rastro, as citações que seguem, todas elas do texto La dissémination, representam (mesmo sabendo que isso não significa que estejam representando alguma verdade, pois não há disfarce quando não há presença primeira, não há metáfora pois não há sentido) o falso início da continuação:

a pena, quando a tenhas seguido, até o fim, terá se transformado em punhal.

Abre, pelo contrário, caminho 'a' semente que não (se) produz, pois não se adianta mais que no plural. Singular plural que nenhuma origem tenha procedido jamais. Germinação, disseminação. Não há primeira inseminação. A semente é, primeiramente, dispersada. A inseminação "primeira" é disseminação. Pegada, enxerto cujos rastros se perdem. Trate-se do que se denomina 'linguagem' (discurso, texto, etc.) ou de inseminação 'real', cada termo é um gérmen, cada gérmen é um termo. O termo, o elemento atômico, engendra se dividindo, enxertando-se, proliferando. É uma semente e não um termo absoluto.

não existe nada antes do grupo, nenhuma unidade simples e originária antes dessa divisão mediante a qual vem a verse a vida e a semente de entrada se multiplica

Página branca, mas escrita desde sempre, branca pelo esquecimento do que foi escrito, por desaparição do texto sobre o fundo do qual tudo que se escreve está escrito. E, no entanto, nada está verdadeiramente escrito, pode mudar a cada instante, e é ainda e interminavelmente a primeira vez.

Se não existe fora-de-texto, é porque a gráfica generalizada começou já sempre, está sempre enxertada em uma escritura 'anterior'. Leem enxertada, sim, e semeando aqui esta alusão ao enxerto, ao transplante, à enfiteuses, premedita ao vê-la germinar em outro lugar e mais adiante.

Nenhum acontecimento é, pois, narrado, tudo acontece no entre-texto, sendo respeitado um único princípio: que não aconteça, no final das contas, nada.

Todos os momentos de polissemia são, como indica o nome, momentos de sentido.

O conceito de polissemia pertence, pois, à explicação, ao presente, da recensão do sentido. Pertence ao discurso da assistência. Seu estilo é o da superfície representada. O enquadramento de seu horizonte se esquece ali. A diferença 
entre a polissemia do discurso e a disseminação textual é justamente a diferença, 'uma diferença implacável'.

Assim se escreve a coisa. Escrever quer dizer enxertar. É a mesma palavra. O dizer da coisa é devolvido ao seu ser-enxertado. $\mathrm{O}$ enxerto não sobrevém ao próprio da coisa. Não há mais coisa que texto original ${ }^{40}$.
${ }^{40}$ DERRIDA. La Diseminación, pp. 551, 453, 455, 463, 490, 501, $525,526,533$.

\section{Referências}

BORGES, Jorge Luis. Obras completas. Vol. IV. $2^{\text {a }}$ ed. Buenos Aires: Emecé, 2003.

BUSSARELLO, R. Dicionário Básico: Latino-Português.

Florianópolis: EDUFSC, 1998.

CULLER, J. Sobre la desconstrucción. Teoría y crítica después del estructuralismo. Trad. L. Clemades, Madrid: Cátedra, 1992.

DERRIDA, Jacques. Gramatologia. $2^{\mathrm{a}}$ ed. Trad. Miriam

Schnaiderman. Perspectiva: São Paulo, 2004.

Posições. Trad. Tomaz Tadeu da Silva. Belo Horizonte:

Autêntica, 2001. La dissémination. Paris: Seuil, 1972. La diseminación. $7^{\mathrm{a}}$ ed. Trad. José Martin Arancibia.

Madrid: Editorial Fundamentos, 1997.

GENETTE, Gérard. Palimpsests. Trad. Channa Newman.

Nebraska: University of Nebraska Press, 1997.

JOHNSON, Barbara. Translator's Introduction. In: Dissemination. Trad. B. Johnson. Chicago: The University of Chicago Press, 1981.

MAJOR, René. Lacan com Derrida. Trad. Fernanda Abreu. Rio de Janeiro: Civilização Brasileira, 2002.

MALLARMÉ, Stéphane. Divagações. Trad. Fernando Scheibe. Florianópolis: Ed. da UFSC, 2010.

Poesias. Trad. Francisco Castaño. $3^{a}$ ed. Madrid:

Hiperión, 2008.

NASCIMENTO, Evando. Derrida e a Literatura. $2^{\text {a }}$ ed. EdUFF, Niterói, 2001.

PERETTI, Cristina de. Jaques Derrida: Texto y Desconstrucción.

Barcelona: Anthropos, 1989. 
PLATÃO. A República. Trad. Carlos Alberto Nunes. $3^{\text {a }}$ ed. Belém: EDUFPA, 2000.

Filebo. Trad. Carlos Alberto Nunes. $3^{a}$ ed. Belém: EDUFPA, 2000. Disponível em: www.livrosgratis.net.

SOLLERS, Philippe. Nombres. Paris: Seuil, 1968.

SANTIAGO, Silviano (dir.). Glossário de Derrida. Rio de Janeiro: Franscisco Alves, 1976. 